\title{
DESIGN RATIONALE IN CONCEPTUAL DESIGN: A LONGITUDINAL STUDY OF PROFESSIONAL DESIGN TEAMS' PRACTICE
}

\author{
L. S. Knudsen ${ }^{1, \bigotimes}$, L. M. Haase ${ }^{1}$ and M. G. Goncalves ${ }^{2}$ \\ ${ }^{1}$ Aalborg University, Denmark, ${ }^{2}$ Delft University of Technology, The Netherlands \\ $\bigotimes$ lsk@create.aau.dk
}

\begin{abstract}
A design rationale is a representation of the reasoning behind a design concept, explaining why the solution is designed the way it is. This makes design rationale a critical part of concept development. However, there is little exploration on how to build a design rationale. This study sheds light on professional designers' reasoning in conceptual design, as we examine how design rationales for different concepts are built based on a longitudinal study in the context of two design studios. Particularly the study provides insight into how a design rationale is initiated, matured and finalized.
\end{abstract}

Keywords: conceptual design, design process, design teams, design rationale, framing

\section{The importance of design rationale in conceptual design}

The kernel of all design efforts is the creation of a concept (Andreasen et al., 2015), thereby developing the core idea that would lead to an effective outcome, which users and other stakeholders would find desirable. A concept must be specified in terms of what the solution should be as well as how it should work by specifying the main features of the future solution such as its shape, components, colours, etc. Each of these elements contributes to how one experiences the solution, and consequently, a critical part of the creation of the concept is the construction of a design rationale. For instance, a loudspeaker consists of many parts, each with its individual purpose, material, shape, etc. Each part contributes to the loudspeaker in a certain way. As individuals we might have different preferences for the particular elements but we perceive the loudspeaker as a whole. Together they make up the thing, and thereby its meaning and significance appear through the ordering and structure of elements (Nelson and Stolterman, 2012) - based on the solution's underlying design rationale. Thereby, building a design rationale can be regarded as a process of composing and connecting elements into a unified whole. In this sense, it is not the individual elements as such that makes the solution unique, but rather the composition of the elements.

\subsection{A definition of design rationale}

A design rationale is defined as "a representation of the reasoning behind the design of an artifact" (Shum and Hammond, 1994, p. 1), thereby explaining why the solution is designed the way it is. A design rationale is hence considered the underlying story of the concept that ties together the different elements of the solution into one coherent argument for the solution as a whole (Shum and Hammond, 1994; Gruber and Russell, 1992). Accordingly, design teams design not only the functional features of the concept but also meaning and significance that the concept might carry. In their work, Shum and 
Hammond (1994) describe the emergence of design rationale as an argumentation process. Their model describes three stages toward a coherent argumentation for a concept: from undeveloped ideas, to partial ideas and finally to manifestation of ideas (Figure 1).

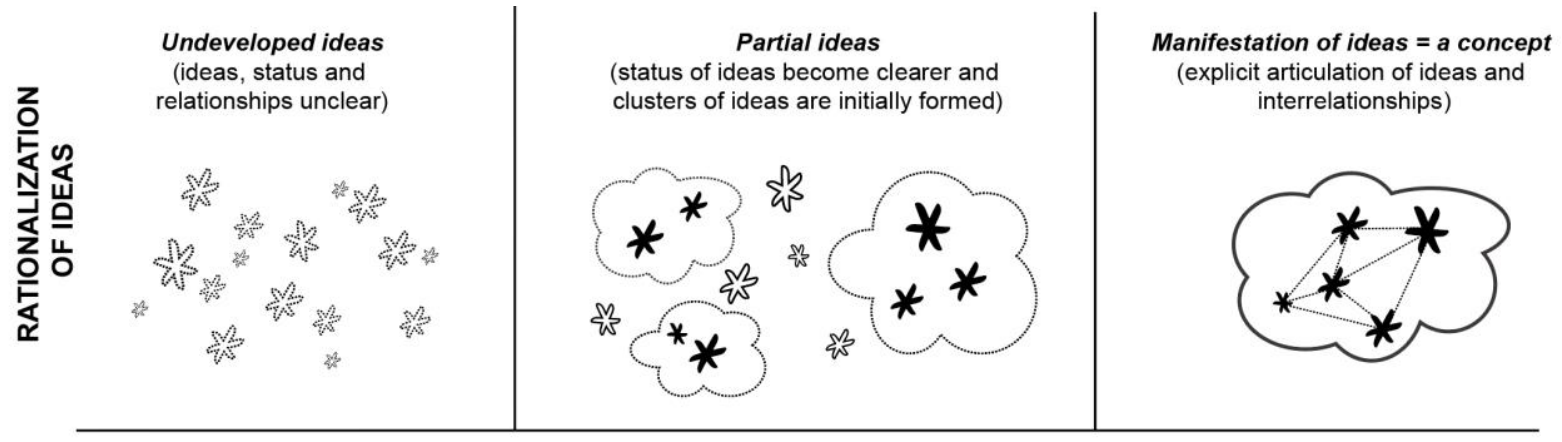

Status of ideas and

interelationships are implicit

No commitment to organize ideas

Few abstractions are made

Status of ideas and interelationships

are explicit

Abstractions are frequent

Commitment to organize ideas

Figure 1. Design rationale as an emergent argumentation process

(based on Shum and Hammond, 1994, p. 38)

At the first stage (undeveloped ideas), ideas are developed without a clear idea of their status or relationships. At this moment, the problem is only vaguely defined, and hence it is not evident which ideas are relevant and why. Accordingly, designers may express themselves ambiguously rather than precisely and explicitly (Shum and Hammond, 1994). At the second stage (partial ideas), initial clusters of ideas are identified based on a matured but still partial understanding of the problem. At the final stage, the problem and the significance of the solution is identified, and thereby ideas are manifested and explicitly articulated into one coherent concept.

Although the model is a simplified version of designers' reasoning process when creating a concept, it provides important clarification to the understanding of design rationale as an underlying justification of ideas that emerges through exploration and experimentation. Thus, the model signifies that a design rationale is not possible to establish upfront the design process because the relevance of one idea may first become apparent when the next ideas render it sensible (Ylirisku et al., 2009). Consequently, designers are forced to commit to the process and proceed without having a full picture of what the problem is (Kolko, 2011).

\subsection{Positioning this study within existing literature}

So far, the notion of 'design rationale' has mainly been discussed in terms of methods to capture and document arguments for decisions during the design process (e.g. Conklin and Begeman, 1988; Lee and Lai, 1991; MacLean et al., 1996). Accordingly, little research has explored how designers reason during conceptualization. To provide clarification of professional designers' reasoning, an important contribution is Schön's work on reflective practice. In his work, Schön (1983) introduced the notion of 'frames' to explain the conceptual structures that guides designers' reasoning. Framing is commonly highlighted as the designer's approach to deal with a problematic design situation. When designers 'frame' a problem they make sense of the situation by creating a redefined view on that problem (Dorst, 2015). The renewed problem understanding then offers a new direction for resolving it. The ability to see design situations in a new way - to reframe the situation - is also referred to as the key expertise of designers (Hey et al., 2007; Paton and Dorst, 2011)

Framing theory provides important contribution to design rationale, as frames can be used to discover the relevance of ideas based on the renewed perspective on the problem (Fisher et al., 1996). However, current studies on framing also leaves a potential gap in research: while framing is commonly discussed as a problem-setting activity, there has been little exploration of how designers move from the overall 
problem framing to the identification and specification of the future solution. Moreover, studies often discuss designers' reasoning as an intuitive and internal process, that is mainly described in terms of overall design activities. Accordingly, it is difficult to find empirical evidence of designers' reasoning process on a content level.

This paper aims to address this gap by examining design rationale as design teams' explicit argumentation of solution elements and hence how they identify and specify the significance of the solution. Based on data from two emergent projects in two design studios, we examine the following research question: How do professional design teams build a design rationale? Our aim is to explore how professional designers reason when they identify relevant ideas, and how those partial ideas are structured into one coherent design rationale. Since literature on design rationale is fairly limited, we build on alternative theories and models that can be used to describe the structure of a design rationale and its elements in the creation of a concept. This forms the theoretical departure for the research which we present in the following section.

\section{Theoretical foundation}

Shum \& Hammond's model (Figure 1) provide a fundamental understanding of the process for which the design rationale is built. But in order to conduct this research, we need to first clarify the critical elements for building a design rationale. Moreover, it is needed to identify what a design rationale may look like when it is composed and fully established.

\subsection{The prerequisites for building a design rationale}

First of all, we found it relevant to develop an understanding of the prerequisites for building a design rationale. In a recent study, the authors concluded that a high quality of insights are needed in order to create significant products (Knudsen et al., 2018). High-quality insights refer to behavioural and contextual aspects, which we thus argue are needed to build a design rationale. Moreover, Knudsen and Haase (2019) identified that professional designers search purposefully for insights that can be used to:

- identify the core challenges in an existing situation (related to social, emotional and functional aspects)

- identify the future context for the solution

- identify tangible solution elements that could meet the core challenges and accentuate the future context

We consider these insights relevant for the construction of the design rationale, and thereby they contribute to our theoretical understanding of the reasoning process in conceptual design.

\subsection{A fully established design rationale}

To provide clarification of a design rationale's composition and elements, we build on a recent study based on expert designers' reasoning. In their study, Knudsen and Haase (2018) found that professional designers reason from a number of frames, in addition to an overall problem frame, when they explain why a product is designed the way it is. Moreover, they showed that designers suggest a frame based on a discovered paradox. A paradox consists of conflicting values, which may emerge because the context for which an existing solution have been used has changed. In Figure 2, we combine this understanding with Haase and Laursen (2017) who argued that each frame and paradox can be viewed in relation to the product's expression, experience, interaction, etc.

Thereby, Figure 2 depicts the design rationale as a construction of a number of different frames and paradoxes. Building on Dorst's (2015) definition, a frame is a constituent of an aspired value and a particular solution principle, which is communicated as a metaphor. Each paradox and connected frame reflect a particular aspect that is deemed important for the solution, such as the solution's expression, experience and interaction. This implies that when a concept is fully established, the design rationale is first of all determined in terms of a leading frame which addresses the main problem. Then, additional frames and paradoxes add further nuances and perspectives to the solution. 
In this way, each frame contributes to the solution in a certain way, and altogether, they form the entire meaning and significance of the solution, i.e. the design rationale.

\begin{tabular}{|c|c|c|c|}
\hline MAIN PARADOX & \multicolumn{3}{|c|}{ LEADING FRAME } \\
\hline $\begin{array}{c}\text { MAIN } \\
\text { PARADOX }\end{array}$ & $\begin{array}{l}\text { ASPIRED } \\
\text { VALUE }\end{array}$ & $\begin{array}{c}\text { FRAME } \\
\text { (METAPHOR) }\end{array}$ & $\begin{array}{l}\text { SOLUTION } \\
\text { PRINCIPLE }\end{array}$ \\
\hline DITIONAL PARADO & \multicolumn{3}{|c|}{ ADDITIONAL FRAMES } \\
\hline $\begin{array}{l}\text { EXPRESSION } \\
\text { paradox }\end{array}$ & $\begin{array}{c}\text { Aspired } \\
\text { EXPRESSION }\end{array}$ & $\begin{array}{l}\text { Framing of } \\
\text { EXPRESSION }\end{array}$ & $\begin{array}{l}\text { EXPRESSION } \\
\text { solution principle }\end{array}$ \\
\hline $\begin{array}{l}\text { EXPERIENCE } \\
\text { paradox }\end{array}$ & $\begin{array}{c}\text { Aspired } \\
\text { EXPERIENCE }\end{array}$ & $\begin{array}{l}\text { Framing of } \\
\text { EXPERIENCE }\end{array}$ & $\begin{array}{l}\text { EXPERIENCE } \\
\text { solution principle }\end{array}$ \\
\hline $\begin{array}{l}\text { INTERACTION } \\
\text { paradox }\end{array}$ & $\begin{array}{c}\text { Aspired } \\
\text { INTERACTION }\end{array}$ & $\begin{array}{c}\text { Framing of } \\
\text { INTERACTION }\end{array}$ & $\begin{array}{l}\text { INTERACTION } \\
\text { solution principle }\end{array}$ \\
\hline ETC. & $\begin{array}{l}\text { Aspired } \\
\text { value }\end{array}$ & $\begin{array}{c}\text { Frame } \\
\text { (metaphor) }\end{array}$ & $\begin{array}{l}\text { Solution } \\
\text { principle }\end{array}$ \\
\hline
\end{tabular}

Figure 2. Design rationale as a composition of paradoxes and frames (based on Knudsen and Haase, 2018)

\subsection{Conceptual model for examining design rationale}

If we combine the insights from the previous findings addressed in this section, it is clear that we can start to understand design rationale as a matter of a compositional assembly that:

1. emerges during conceptual development

2. is initially approached by developing insights on core challenges, future context and solution elements

3. is structured as a set of frames and paradoxes (that is when the design rationale is established)

These theoretical insights on design rationale is combined in a conceptual model (Figure 3).
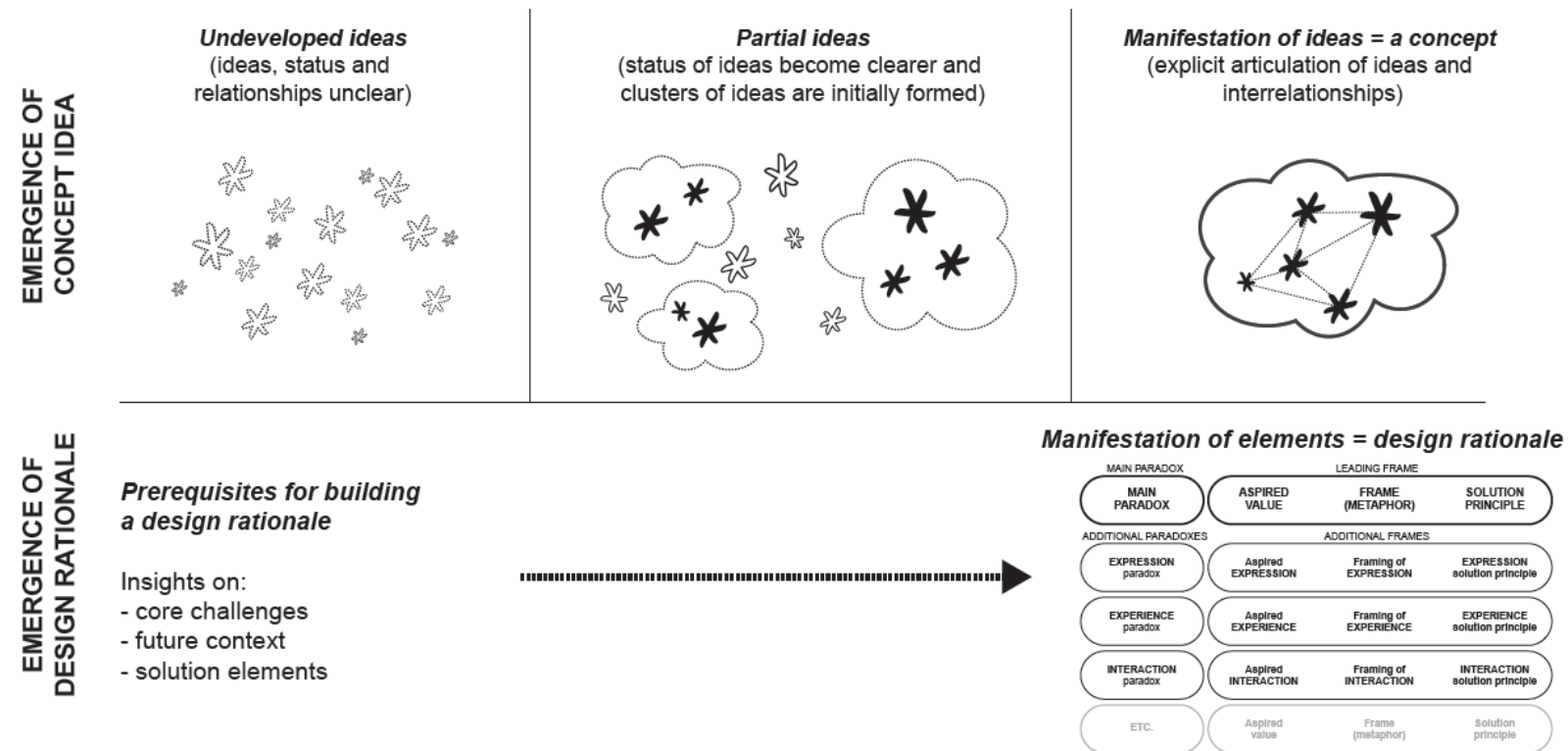

Figure 3. Conceptual model for design rationale

Based on our conceptual model (Figure 3), we explore how a design rationale is initiated, matured and finalized. In particular, it is examined how design teams move from the prerequisites to a structured 
design rationale (the arrow in Figure 3) that determines the initial criteria for the evaluation of the solution.

\section{Research design}

In order to investigate how professional design teams build a design rationale in conceptual development, a case study approach was selected for this study. The two longitudinal cases constitute two Dutch design studios, each working on a project for their respective client.

To obtain as rich information as possible, we followed the two projects intensively during the conceptual phases through observations of daily internal meetings and workshops combined with follow-up interviews. At the meetings and workshops that took place in the studio, the main researcher was non-participant, as this provided the most natural and normal behaviour among the team members without interfering with their daily work routines or taking the risk of biasing the data. The meetings and workshops were followed up with short interviews with the designers to capture their immediate reflections on the process and clarify topics addressed during their discussions. Furthermore, the dataset was supplemented with continuous qualitative interviews with the project/design lead to catch up on actions and decisions made outside of the meeting room.

As we aimed for an intensive and in-depth analysis to examine design rationale, we focused on only these two cases. Furthermore, we chose a case selection strategy that is based on 'maximum variation cases' "to obtain information about the significance of various circumstances for case process and outcome" (Flyvbjerg, 2006, p. 230). The two cases were selected due to their maximum variation regarding the project type: one deals with a redesign of an aid (product design), whereas the other one deals with the development of a future city hotel concept (service design). Another contrast is that user research plays a key role in the service design project whereas there is no budget for user research in the product design case. Thereby findings are identified independently of the type of project. Both studios are selected due to their high-quality portfolio representing a variety of clients across different industries, while the specific cases are selected together with the project lead based on their representativeness for the research focus. Table 1 summarizes the two cases included in the study.

Table 1. Cases included in the study

\begin{tabular}{|c|c|c|c|}
\hline Case/studio & Brief/project type & $\begin{array}{c}\text { Team } \\
\text { composition }\end{array}$ & Dataset \\
\hline $\begin{array}{l}\text { Design studio A: } \\
\text { One of the first product } \\
\text { design consultancies in the } \\
\text { Netherlands, having an } \\
\text { important role in defining } \\
\text { Dutch product design. They } \\
\text { won a large list of awards in } \\
\text { their } 40 \text { years of existence. }\end{array}$ & $\begin{array}{l}\text { Developing a } \\
\text { compression } \\
\text { stocking aid } \\
\text { (product design). } \\
\text { No user research in } \\
\text { the conceptual } \\
\text { phases }\end{array}$ & $\begin{array}{l}\text { Design lead } \\
\text { (industrial } \\
\text { designer), senior } \\
\text { industrial } \\
\text { designer, design } \\
\text { engineer }\end{array}$ & $\begin{array}{l}\text { Observations of } 3 \\
\text { workshops/meetings (transcribed) } \\
\text { incl. field notes, } \\
5 \text { interviews (transcribed) incl. field } \\
\text { notes } \\
\text { Project brief, presentation material, } \\
\text { desk research data, early drawings, } \\
\text { prototypes, workshop material }\end{array}$ \\
\hline $\begin{array}{l}\text { Design studio B: } \\
\text { One of the first service } \\
\text { design consultancies in the } \\
\text { world, now representing } 3 \\
\text { studios worldwide. The } \\
\text { studio pioneered the } \\
\text { application of service design } \\
\text { in public and private sectors, } \\
\text { and has now existed for } \\
\text { around } 20 \text { years. }\end{array}$ & $\begin{array}{l}\text { Developing a new } \\
\text { hotel experience } \\
\text { (service design). } \\
\text { Intensive user } \\
\text { research in the } \\
\text { conceptual phases }\end{array}$ & $\begin{array}{l}\text { Project } \\
\text { manager, senior } \\
\text { service designer, } \\
\text { junior service } \\
\text { designer, insight } \\
\text { lead }\end{array}$ & $\begin{array}{l}\text { Observations of } 4 \\
\text { workshops/meetings (transcribed) } \\
\text { incl. field notes, } \\
6 \text { interviews (transcribed) incl. field } \\
\text { notes } \\
\text { Project brief, presentation material, } \\
\text { desk research data, user research } \\
\text { data, early drawings, prototypes, } \\
\text { workshop material }\end{array}$ \\
\hline
\end{tabular}

\section{Cases: Empirical foundation}

To fully understand the context from which the findings are generated, the two cases are introduced in the following section. Due to confidential material in the projects, we will not show any content from the 
cases nor reveal the names of the design studios, but they will be described in general terms. Moreover, we will not address the final solutions as this study is centred only on the conceptual phases.

\subsection{Development of a compression stocking aid (Case A)}

This project deals with the development of a compression stocking aid. The project is initiated by the client company who has developed a first version of a stocking aid which is intended for elderly and obese people. This target group are frequent users of compression stockings but they often encounter challenges to apply it due to limited mobility and strength. The idea of the current device is to help the user applying the stocking without support from daily homecare. A proper application of the stocking is often a difficult challenge, and the design of a better solution has been attempted by several companies. What is different from similar aids on the market is that the client's device has a motorized function to open up the stocking, which makes the opening easier than the ones offered by competitors. However, the client is not yet satisfied with their current product and therefore asks the design studio to improve it. The design team did not receive any information about what to improve but is only provided with the client's current physical device. In this sense, the brief was quite open when the team started on the project.

\subsection{Development of a new city hotel experience (Case B)}

In this case, the service design studio deals with the development of a new city hotel experience, a project initiated from a client who is a mature current player in the hospitality industry. The hotel branch is very competitive and growing fast, however the client had discovered a gap and potential opportunity in the market: there seems to be a lot of luxury hotels as well as budget hotels - but not so much in between. Despite the client's large experience in hospitality, they need support to design the next future experience of a hotel concept. As such, the brief is quite open and the main question for the design team is: what kind of experience should a new hotel concept in the European city centers deliver to the guests?

\section{Analysis and findings}

This section presents the results based on the dataset from the two cases. The analysis was based on the transcribed meetings and interviews, where themes retrieved from the elements of a design rationale identified in our conceptual model. From the analyses, some overall findings emerged, related to how the teams initiate, mature and finalize the design rationale. These findings are explained in the following section and are supported by direct quotes retrieved from the design meetings and interviews.

\subsection{The design teams initiate the design rationale by organizing the core challenges in respect to the key aspects of the solution}

The first finding that appeared across the two cases is related to how the design teams initiated the design rationale. In particular, the teams developed initial insights on core challenges based on their own experiences with existing solutions. Furthermore, they attempted to organize the core challenges in respect to key aspects, such the solution's expression, experience and interaction.

For instance, at the very first meeting in the studio (case A), the team identified core challenges related to experience, expression, interaction and technology. These challenges were mainly based on the client's existing stocking aid combined with a desk research on similar products on the market. Thereby, the initial insights were based on the team's own experiences and interpretations, which became the starting point for building the design rationale.

One core challenge regarding the existing experience was the following: due to its pistol shape, its associations to tools and its sound similar to a power drill, the aid evoked a machine feeling. According to the team, a machine feeling is not what one would like in this context, and it could feel uncomfortable to use the device in relation to the body. The following quotes from their discussions about the existing device point clearly to the core challenge: "Oh my God, what am I putting around my leg?!" and "It feels very scary and uncomfortable". As such, the user experience of the future solution is a key aspect that needs to be considered in the future solution. Another key aspect that the team payed attention to was the expression of the current device. As the following quote emphasises, its medical expression and 
its drill shape are regarded as a core challenge: "Why is it white? It doesn't need to be white. And with the green it is very medical. And with the drill! The black drill... I actually feel a bit handicapped or stigmatized with it". As such, stigmatization was another core challenge related to the expression of the device, and thereby, the expression was initially a key aspect to address in the future solution.

In Case B, the core challenges that the team identified were related to interaction, experience, features and sustainability. Also in this case, the challenges are based on the designers' own experiences with existing solutions (in this case, their own experiences of being a guest in different types of hotels).

One example of a core challenge that points to interaction as a significant aspect is the following quote from one of the first design meetings where they addressed the check-in situation: "I really hate when they [the staff, red.] are typing in... it's just a silly interaction. Pure lameness. What are you doing with my passport? All I want is to get my room. It's a completely empty interaction! But if all that is automated and the person says hello to me, then it means something." Hence, the interaction with the staff is a critical point for the whole hotel experience, and therefore the solution's interaction is deemed a key aspect. Another core challenge is related to the functional elements provided in many hotels: "Essentially, nobody needs all the additional crap you get. They are always innovating on a metric that is not relevant. Your bath becomes bigger or your towel gets thicker... And stuff you don't need." In this quote one of the designers addressed the significance of the features provided in the hotel: unnecessary details without a clear purpose. This is regarded as a very critical aspect for the entire hotel experience, and thereby features became a main aspect to address in the future solution. In the same way, the team identified core challenges related to experience and sustainability, which initiated the relevant aspects for the underlying design rationale for the future hotel concept.

\subsection{The design teams mature the design rationale by focusing on one particular aspect at the time}

While the core challenges of existing solutions determined the key aspects of the future solution, another finding is that the teams focused on one particular aspect (e.g. interaction) at the time in the building of the design rationale. In particular, they shifted between insights on core challenge, future context and solution principles within each particular aspect. Hence, the teams pursued identification of relevant connections between those insights, and thereby the teams developed a sense of direction for each particular aspect (e.g. the ideal expression, interaction and experience). This finding is exemplified in the following.

In the aforementioned section, we addressed how the team in case A focused on the expression as one key aspect of the future solution. The core challenge regarding the expression was the medical look and drill associations. Based on this challenge, the team further focused on the expression in terms of the future context and solution principles for the future solution. For instance, the following quote illustrates how the design team addressed the future context: "Most of the time it is more like a piece of clothing... I put on my bra, my stocking... it's standing in my bedroom. It's not in a medical environment... it's in a wardrobe environment, I would say. It should look more like a hairdryer, right? Not like a drill." From this quote it is clear that they pointed to a different context for the future solution (wardrobe environment). Moreover, they discussed how to accentuate this context by proposing concrete solution principles for the future product's expression: "If it's my device I would like to have it as small as possible. And also the weight... it should be something that can be easily stored, light-weight and into as small as possible size." Even though these are only fragmented quotes from their discussion, they illustrate how they attempted to connect the core challenge, future context and solution principles in order to develop a direction for the solution's expression.

Likewise, another core challenge that the team addressed was related to the interaction and use of the current aid: "You don't see what direction of the sock should be, or the direction of the handles on the device. Based on the distribution of weight, you would expect it to be the other way around, the motor pointing downward, but based on the allocated space for the foot, it is 180 degrees opposite so it is very unclear." A proper application is critical for the effect of the stocking, and thereby the interaction became a key aspect to address in the future solution. Similar to the abovementioned example, the team further discussed the future context for the product's interaction: "We should focus on making it a bit more organic and understandable as a product. The more technical in its use, the more distance to the user". Furthermore, they focused on solution principles that could meet the core challenge and accentuate the 
future context: "The orientation should be taken into account when applying the sock to the device. Maybe if we have a round shape, the orientation of the sock could be done afterwards." In this way, the process followed as a continuous discussion where the team shifted between the elements in order to develop a direction for the future solution's interaction.

In the hotel case (case B), one core challenge addressed the interaction between the hotel and the traveller. In the example from the previous section, they focused specifically on the checking-in situation, which was identified as being a critical point for the entire hotel experience. Their ongoing discussions focused on the balance between a high-tech solution (no interaction with staff) and hightouch-solution (a lot of interactions with staff), which both addressed shortcomings for the user. Accordingly, they explored the important moments of interactions. In the following quote one of the designers pointed to a future context, that initiated an essential direction for the interaction: "So there seems to be this home-coming feeling that is much more about someone looking in the eyes than somewhere to hang your coat." In the followed process a 'warm welcome' became a main topic for their discussion about interaction. Another example is: "Recognition is interesting... That you are acknowledged by the staff... they see me. They know that I need a hairdresser every time I'm there. But also as a new person, that you are acknowledged as a human being rather than just another guest." They further discussed how to accentuate this interaction point through concrete solution principles: "If you can automate, then automate it. But don't automate the welcoming and goodbye." In this way, they attempted to specify a direction for the solution's interaction. In the same way they continued focusing on the other aspects, one by one, for the experience, features and sustainability.

\subsection{The teams finalize the design rationale by prioritizing one key aspect}

In the previous section, we illustrated how the teams set an initial direction for each particular aspect for the future concept. The last significant pattern was that the teams searched for the most important aspect in order to finalize the design rationale. This aspect set the leading identity for the concept, which helped building up the design rationale, supported by the leading aspect. We illustrate this finding in the following section.

Based on their discussions in case A, it was clear that the expression was regarded as the most critical aspect of the future solution. The expression of the current device evoked very emotional feelings for the user, stigmatizing the user into a medical context. The functionality was also considered critical but the expression was the most essential for the overall user experience. Hence, the future context of the wardrobe environment 'just like a hairdryer' became more than the just the expression; rather it set the overall identity of home appliance that tied together the entire concept. Hence, 'home appliance' became the leading principle that helped specifying the solution in terms of the product's interaction, experience and technology. For instance, in a home appliance product, the interaction should be "self-evident without a certain orientation". Furthermore, the aspired experience should "serve a gentle gesture", and the technology should be integrated as "invisible technology". Those principles together constituted the cornerstones for the design rationale (see Figure 4).

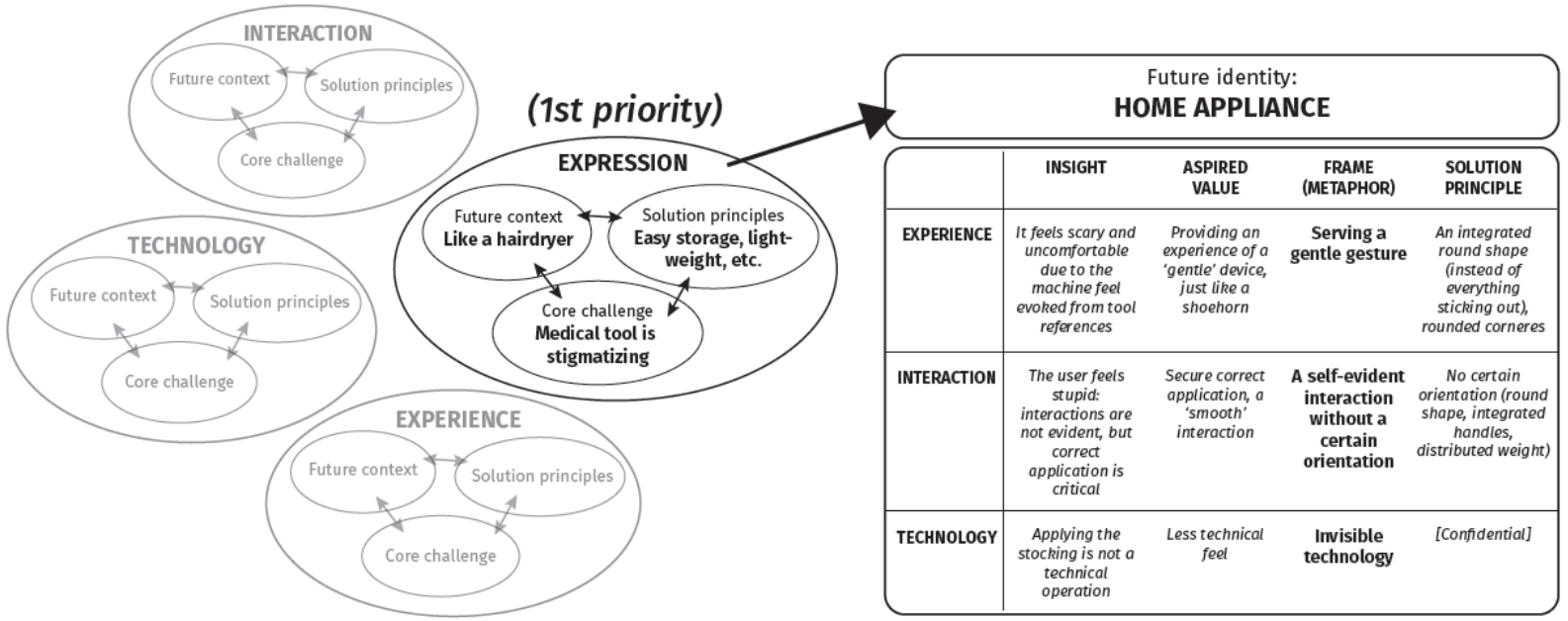

Figure 4. Case A: One key aspect (future identity 'home appliance') leads the design rationale 
Likewise, at some point in case B, the team discovered a key insight on the staff's role, based on their user research. The following quote from their discussion about the role of the staff illustrates this insight: "What was interesting was that they [the travellers, red.] don't really need the staff but it was really nice that they were there. Personal but not too personal right?... So a safety net... Hey, they are the base! It's them!" This quote indicates that the function of the staff is a key factor for the entire hotel experience. Thereby, the warm welcome interaction triggered the whole identity for the hotel paraphrased as 'genuine hospitality'. This identity helped to further specify the future hotel in terms of the solution's features, experience and sustainability (see Figure 5).

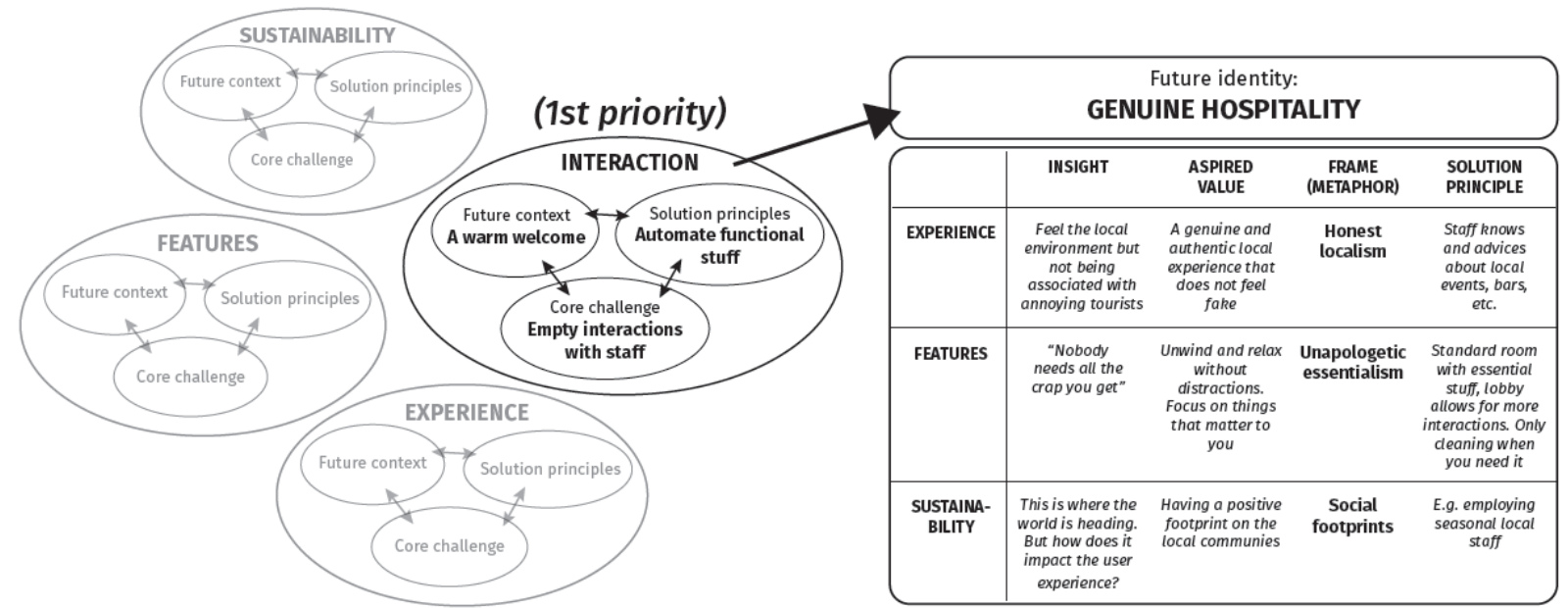

Figure 5. Case B: One key aspect (future identity 'genuine hospitality') leads the design rationale

\section{Discussion and conclusion}

The aim of this study was to better understand expert design teams' reasoning during conceptualization. The paper addressed how design teams arrive to design rationale, which provides a meaningful experience for the user. However, literature on design rationale is fairly limited in the field of product and service design, and especially longitudinal and situated studies are scarce. We therefore examined the emergence of design rationale based on a case study approach, through which we collected a rich dataset through observations and interviews in two professional design studios. Based on the dataset we examined how expert design teams built a design rationale. This revealed three main findings:

a) The design teams initiate the design rationale by organizing the core challenges in respect to the key aspects of the solution

b) The design teams mature the design rationale by focusing on one particular aspect at the time

c) The teams finalize the design rationale by prioritizing one key aspect

When we interpret these findings, it is relevant to consider the following limitations. In order to examine the construction of design rationale, we chose to focus only on two cases to enable an indepth analysis of designers' reasoning. Moreover, we focused only on the conceptual phases because designers will most often search for a framing in the beginning of a project. Finally, we acknowledge that small decisions and framing moments can happen all the time (even in small informal conversations within the team) and have a big influence on how the design rationale is created. For this reason, we suggest further avenues for future research on design rationale to take place. More empirical evidence is needed to support our findings, and to build a robust framework for the construction of a design rationale. It would be interesting to further examine how to support design teams in building design rationales, and thereby arriving in meaningful and significant solutions.

This study on design rationale is relevant because we can now start to address conceptualization on a more operational and explicit level than previously discussed in research. In general, conceptualization is discussed as the most mysterious and less understood part of designing (e.g. Ylirisku, 2013; Kolko, 
2011). Yet it happens to be the phase where the most important decisions are made (McNally and Schmidt, 2011; Hauser et al., 2006). By shedding light to the concept's underlying design rationale, the findings can provide important contribution to our understanding of conceptualization by making the implicit reasoning process explicit. Hence, it brings the possibility to make the conceptualization process more conscious, and thereby support creation of explicit arguments in the design process. Such information might be critical for all stakeholders involved in the design process, for instance to provide a clear direction for the intended concept idea, and thereby ensuring it is articulated through the realization and implementation of the final solution.

\section{References}

Andreasen, M.M., Hansen, C.T. and Cash, P. (2015), Conceptual Design: Interpretations, Mindset and Models, Springer.

Conklin, J. and Begeman, M.L. (1988), “GIBIS: A Hypertext Tool for Exploratory Policy Discussion”, Proceedings of the 1988 ACM Conference on Computer-Supported Cooperative Work, CSCW 1988, Vol. 6 No. 4, pp. 303-331.

Dorst, K. (2015), "Frame Innovation: Create New Thinking by Design", In: Friedman, K. and Stolterman, E. (Ed.), The MIT Press, London, England.

Fischer, G. et al. (1996), "Making Argumentation Serve Design", In: Carroll, J.M. and Moran, T.P. (Ed.), Design Rationale: Concepts, techniques, and Use. Lawrence Erlbaum Associates, pp. 267-294.

Flyvbjerg, B. (2006), "Five misunderstandings about case-study research", Qualitative Inquiry, Vol. 12 No. 2 , pp. 219-245.

Gruber, T.R. and Russell, D.M. (1992), "Derivation and use of design rationale information as expressed by designers".

Haase, L.M. and Laursen, L.N. (2017), "Framing Innovation : Product Reasoning Model for Early Phase Innovations", in ISPIM Innovation Symposium 2017: Building the Innovation Century. The International Society for Professional Innovation Management (ISPIM)

Hauser, J. et al. (2006), "Research on Innovation: A Review and Agenda for 'Marketing Science'”, Marketing Science Marketing Science, Vol. 25 No. 6, pp. 687-717.

Hey, J., Joyce, C.K. and Beckman, S.L. (2007), "Framing innovation: negotiating shared frames during early design phases", Journal of Design Research, p. 6.

Knudsen, L.S. and Haase, L.M. (2018), "The Construction of Meaning in Design-Driven Projects: A Paradox Initiated Process", International Journal of Design Creativity and Innovation, Vol. 7 No. 3, pp. 129-143.

Knudsen, L.S. and Haase, L.M. (2019), “'Seeking Insights into an unknown Future: Exploring Designers' Strategies to Discover Key Insights"”, in Proceedings of the Design Society: International Conference on Engineering Design, Vol. 1 No. 1, pp. 3999-4008.

Knudsen, L.S., Tollestrup, C. and Haase, L.M. (2018), “The Characteristics of Successful Meaning Construction in Design Teams", In: Marjanović, D. et al. (Ed.), International Design Conference - Design 2018, pp. $793-804$.

Kolko, J. (2011), Exposing the Magic of Design: A Practitioner's Guide to the Methods and Theory of Synthesis, Oxford University Press, New York.

Lee, J. and Lai, K.-Y. (1991), “What's in Design Rationale?” In: Moran, T.P. and Carroll, J.M. (Ed.), Design Rationale: Concepts, Techniques, and Use, Lawrence Erlbaum Associates, Mahwah, New Jersey, pp. 21-51.

MacLean, A. et al (1996), "Questions, Options, and Criteria: Elements of Design Space Analysis”, In: Moran, T.P. and Carroll, J.M., (Ed.), Design Rationale: Concepts, Techniques, and Use, Lawrence Erlbaum Associates, pp. 53-106.

McNally, R.C. and Schmidt, J.B. (2011), "From the special issue editors: An introduction to the special issue on decision making in new product development and innovation”, Journal of Product Innovation Management, Vol. 28 No. 5, pp. 619-622.

Nelson, H.G. and Stolterman, E. (2012), The Design Way: Intentional Change in an Unpredictable World., 2nd edn, The MIT Press, London, England.

Paton, B. and Dorst, K. (2011), "Briefing and reframing: A situated practice”, Design Studies. Elsevier Ltd, Vol. 32 No. 6, pp. 573-587.

Schön, D.A. (1983), The Reflective Practitioner: How Professionals Think in Action, Basic Books, New York.

Shum, S.B. and Hammond, N. (1994), "Argumentation-Based Design Rationale: What Use at What Cost?", International Journal of Human-Computer Studies, Vol. 40 No. 4, pp. 603-652.

Ylirisku, S. et al. (2009) 'Framing Design in the Third Paradigm', in Proceedings of the 27th Conference on Human Factors in Computing Systems CHI 2009. ACM, pp. 1131-1140.

Ylirisku, S. (2013) Frame it simple: Towards a Theory of Conceptual Designing. Aalto University. 